\title{
Origin of lactic acid bacteria in mulkimchi fermentation
}

\author{
Chung Eun Hwang ${ }^{1} \cdot$ Md. Azizul Haque ${ }^{2} \cdot$ Su Young Hong ${ }^{3}$ Su Cheol Kim ${ }^{1}$. \\ Kye Man $\mathrm{Cho}^{1}$ (D)
}

Received: 5 September 2019 / Accepted: 22 November 2019 / Published Online: 31 December 2019

(C) The Korean Society for Applied Biological Chemistry 2019

\begin{abstract}
The assortment of endophytic lactic acid bacteria (LAB) in kimchi derives from its raw vegetables, which include Chinese cabbage, radish, welsh onion, onion, garlic, red pepper, and ginger. These vegetables were examined during mulkimchi fermentation using gene-specific multiplex polymerase chain reaction and $16 \mathrm{~S}$ ribosomal RNA sequence analysis. Sixteen species from five LAB genera (Leuconostoc, Lactobacillus, Lactococcus, Pediococcus, and Weissella) appeared in the raw kimchi materials. Interestingly, nine LAB species were identified in mulkimchi on fermentation day 0 as follows: Leuconostoc carnosum, Leuconostoc citreum, Leuconostoc gelidum, Leuconostoc inhae, Leuconostoc mesenteroides, Lactobacillus plantarum, Lactobacillus sakei, Lactococcus lactis, and Weissella confusa. Seven additional LAB species were present in mulkimchi at fermentation day 9 as follows: Leuconostoc gasicomitatum, Leuconostoc kimchii, Lactobacillus brevis, Lactobacillus curvatus, Lactobacillus pentosus, Pediococcus pentosaceus, and Weissella koreensis. These species corresponded completely with the LAB in kimchi vegetables. Wei. confusa was the predominant LAB during early fermentation ( $\mathrm{pH} 6.20$ to 4.98 and acidity 0.20 to 0.64\%), while Lac. sakei, Lac. plantarum, and Wei. koreensis became dominant later in fermentation $(\mathrm{pH} 4.98$ to 3.88 and acidity 0.64 to $1.26 \%$ ). These results collectively demonstrate that
\end{abstract}

Kye Man Cho $(\bowtie)$

E-mail:kmcho@gntech.ac.kr

${ }^{1}$ Department of Food Science, Gyeongnam National University of Science and Technology, Jinju 52725, Republic of Korea

${ }^{2}$ Department of Biochemistry \& Molecular Biology, Hajee Mohammad Danesh Science \& Technology University, Dinajpur 5200, Bangladesh

${ }^{3}$ Food Science Research Institute, SBT Business Division, Kolmar BNH Inc., Sejong 30003, Republic of Korea

This is an Open Access article distributed under the terms of the Creative Commons Attribution Non-Commercial License (http://creativecommons org/licenses/by-nc/3.0/) which permits unrestricted non-commercial use, distribution, and reproduction in any medium, provided the original work is properly cited. the LAB involved in mulkimchi fermentation originates from the raw vegetables examined.

Keywords Endophytic $\cdot$ Kimchi-vegetables $\cdot$ Lactic acid bacteria Mulkimchi $\cdot$ Multiplex-PCR · Origin

\section{Introduction}

Kimchi is a Korean traditional fermented vegetable that is typically composed of the following components: Chinese cabbage, radish, green onion, red pepper powder, garlic, ginger, and fermented sea food. Because failures in the fermentation of kimchi occur often, efforts are being made to control the fermentation process. Specifically, the main bacterial species that are actively involved in the raw materials (vegetables) and in the fermentation process need to be identified. Most of the lactic acid bacteria (LAB) was previously isolated and identified from fermented kimchi and includes Leuconostoc mesenteroides, Leuconostoc citreum, Leuconostoc gasicomitatum, Lactobacillus brevis, Lactobacillus curvtaus, Lactobacillus plantarum, Lactobacillus sakei, Lactococcus lactis, Pediococcus pentosaceus, and Weissella koreensis [1-5]. A soup-based Korean food known as mulkimchi is prepared from fermented kimchi and fresh red peppers, which can be acidified and softened more rapidly by LAB than can other kimchi.

Fermentation by LAB can reduce the microbial contamination and inhibit the growth of foodborne pathogens in fermented foods [6]. Several studies have reported the role of LAB in different phases of kimchi fermentation [4,7,8]. Previously, Cagno et al. [9] emphasized the role of LAB involvement in the spontaneous fermentation of fruits and vegetables. However, the origin of the fermenting LAB in kimchi remains unclear [10-12].

We previously designed sets of special multiplex PCR primers for the rapid detection of $\mathrm{LAB}$ during baechukimchi fermentation [3]. In this study, we identified the endophytic LAB species of raw 
kimchi materials (vegetables), including Chinese cabbage, radish, welsh onion, onion, garlic, red pepper, and ginger as well as the LAB species of mulkimchi prepared from all of these vegetable mixtures, using multiplex polymerase chain reaction (PCR) and 16S ribosomal RNA (rRNA) sequence analysis.

\section{Materials and methods}

\section{Bacterial strains and growth medium}

The LAB were grown overnight at $30^{\circ} \mathrm{C}$ in Lactobacilli MRS broth/agar (MRSB/MRSA, Difco, Becton Dickinson Co., Sparks, MD, USA). Escherichia coli $\mathrm{DH} 5 \alpha$ and recombinant $E$. coli cells were cultured in LB (Becton Dickinson Co.) media containing the appropriate antibiotics (ampicillin, $50 \mu \mathrm{g} / \mathrm{mL}$ ) at $37{ }^{\circ} \mathrm{C}$.

\section{Preparation of raw kimchi materials and mulkimchi}

Seven raw materials, including Chinese cabbage (CC), young radish (YR), welsh onion (WOn), onion (On), garlic (Ga), red pepper (RPe), and ginger (Gi), were obtained from Gyeongnam Agricultural Research and Extension Services in the Jinju area of Korea and transferred to a sterile bag for same-day analysis. The root and leaf surfaces of CC, YR, WOn, On, Ga, RPe, and Gi were disinfected with $1 \%$ sodium hypochlorite for $10 \mathrm{~min}$. The external portion of the roots (approximately $0.5 \mathrm{~cm}$ from the margin) was removed with a sterile blade, and the root tissue was triturated in a sterile porcelain mortar in sterile $10 \mathrm{mM}$ phosphate buffer ( $\mathrm{pH}$ 7.2) [13]. One hundred microliters of samples were spread-plated on MRS agar and incubated at $30{ }^{\circ} \mathrm{C}$ for $48 \mathrm{~h}$. All raw materials from kimchi sources were washed with tap water and sliced to prepare mulkimchi as previously described [14]. Prepared mulkimchi samples were placed in a capped $1,000 \mathrm{~mL}$ glass jar $(1,800 \mathrm{~mL})$ and fermented at $25^{\circ} \mathrm{C}$ for $6 \mathrm{~h}$ and then at $8^{\circ} \mathrm{C}$ for 30 days. One hundred grams [Solutions of mulkimchi: solids of mulkimchi $=4(80 \mathrm{~g}): 1(20 \mathrm{~g})]$ of each mulkimchi sample (was collected at $0,3,6,9,12,18,24$, and 30 days of fermentation.

\section{pH and acidity}

The $\mathrm{pH}$ and acidity of each blended mulkimchi sample was measured according to Cho et al. [14]. Briefly, one hundred grams of each mulkimchi sample was ground with a brand blender and after each blended sample was filtered to collect the fluid portion and the $\mathrm{pH}$ was measured with a $\mathrm{pH}$ meter (MP $220 \mathrm{pH}$ meter, London, UK). To estimate the acidity, $20 \mathrm{~mL}$ of mulkimchi filtrate was titrated with $0.1 \mathrm{~N} \mathrm{NaOH}$ at $\mathrm{pH} 8.2 \pm 0.2$.

Total viable LAB cells and isolation of LAB from mulkimchi samples

The total LAB cell numbers in the mulkimchi samples were determined on MRS agar plates, and colony counts were carried out according to Cho et al. [14]. In short, $1 \mathrm{~mL}$ of each blended mulkimchi sample was diluted in $9 \mathrm{~mL}$ of sterile $0.85 \% \mathrm{NaCl}$ water. Aliquots of $1 \mathrm{~mL}$ were serially diluted ten-fold using the buffer and $100 \mu \mathrm{L}$ samples were spread-plated on MRS and incubated at $28^{\circ} \mathrm{C}$ for $48 \mathrm{~h}$.

\section{Extraction of total DNA from LAB}

Genomic DNA was extracted as described in the total DNA extraction G-spin ${ }^{\mathrm{TM}}$ Genomic DNA Extraction Kit (iNtRON Biotechnology, Suwon, Korea) or by boiling and vortexing the bacterial pellets for $10 \mathrm{~min}$ at $80^{\circ} \mathrm{C}$. The extracted DNA was used as a template for the multiplex PCR.

Primers, multiplex PCR reaction, and agarose gel electrophoresis Ten species-specific primers were designed for the PCR application of Leu. carnosum, Leu. mesenteroides, Lac. brevis, Lac. plantarum, Lac. pentosus, Lac. sakei, Lac. lactis, Ped. pentosaceus, Wei. confusa, and Wei. koreensis, and multiplex PCR was performed as previously described [3]. The PCR reaction mixture $(50 \mu \mathrm{L})$ consisted of $5 \mu \mathrm{L}$ of template DNA, $2 \mu \mathrm{L}$ each of mixture of ten primer sets (20 pmol, Bioneer Co., Daejeon, Korea), $5 \mu \mathrm{L}$ of reaction buffer with $2.5 \mathrm{mM} \mathrm{MgCl} 2,5 \mu \mathrm{L}$ of $2.5 \mathrm{mM}$ deoxynucleoside triphophate, $1 \mu \mathrm{L}$ of Super-Therm DNA polymerase (5.0 unit, JMR, Side Cup, Kent, UK), and $30 \mu \mathrm{L}$ of sterile water. Multiplex PCR was carried out through 40 cycles following a preheat step at $95{ }^{\circ} \mathrm{C}$ for $5 \mathrm{~min}$. Each cycle designed of denaturation at $94{ }^{\circ} \mathrm{C}$ for $30 \mathrm{~s}$, annealing at $60{ }^{\circ} \mathrm{C}$ for $1 \mathrm{~min}$, and extension at $72{ }^{\circ} \mathrm{C}$ for $2 \mathrm{~min}$. The final step was followed by a last extension at $72{ }^{\circ} \mathrm{C}$ for $10 \mathrm{~min}$. The PCR products were analyzed by agarose gel electrophoresis as described by Cho et al. [14]. Additionally, the unidentified LAB confirmed by $16 \mathrm{~S}$ rRNA gene sequencing.

\section{S rRNA PCR and sequence analysis}

$\mathrm{LAB}$ isolates that remained unidentified by multiplex PCR were subjected to further analysis via 16S rRNA gene sequencing. To amplify the 16S rRNA gene fragments, the following universal PCR primers were used: Forward, 5'-CGGAGAGTTTPATCC TPG-3'; reverse, 5'-TACGGCTACCTTPTTAGCGAC-3'. The 16S rRNA genes were amplified by PCR, and these sequences were analyzed as previously described [15].

\section{Results and Discussion}

Distribution of endophytic LAB from raw kimchi materials This study was initiated to explore the endophytic LAB communities in raw kimchi materials (vegetables) and during mulkimchi fermentation periods using our previously developed multiplex PCR [3] and 16S rRNA sequence methods. When multiple targetbacteria were included in a reaction mixture containing ten primer-sets, corresponding amplicons of different sizes were observed. Each species-specific primer set produced a single PCR product with an expected product size that corresponded to the 
species specificity of the primer set [3]. Instead of 16S rRNA, the multiplex PCR primer sets contained 10 different gene sequences, which successfully identified the LAB in the raw vegetables and in the mulkimchi samples examined in this study. Additionally, the 16S rRNA gene sequence primers identified LAB that were otherwise not identifiable using the gene-specific multiplex PCR assay.

The distribution of $\mathrm{LAB}$ was assessed in samples obtained from CC, Ra, WOn, On, Ga, RPe, and Gi plants. Total LAB cell numbers varied from 1.24 to $2.53 \mathrm{log} \mathrm{cfu} / \mathrm{g}$ of the raw materials. A total of 515 colonies were isolated from the CC, Ra, WOn, On, $\mathrm{Ga}, \mathrm{RPe}$, and $\mathrm{Gi}$ roots and leaves. The $\mathrm{CC}$ root sample consisted of 92 isolates representing 12 species, which included Leu. carnosum, Leu. citreum, Leu. gelidum, Leu. inhae, Leu. mesenteroides, Lac. brevis, Lac. plantarum, Lac. sakei, Lac. lactis, Ped. pentosaceus, Wei. confusa, and Wei. korenesis. The CC leaf sample consisted of 88 isolates representing 10 species that corresponded to the CC root sample, not including Leu. inhae, Lac. brevis, and Ped. pentosaceus. Additionally, it consisted of one unique isolate-Leu. kimchii. The Ra root sample consisted of
45 isolates representing 13 species that corresponded to the $\mathrm{CC}$ root sample, not including Leu. carnosum and Leu. gelidum. However, the Ra leaf sample provided 40 isolates representing 9 species that corresponded to the $\mathrm{CC}$ root sample, not including Leu. gelidum, Leu. inhae, Lac. brevis, Leu. kimchii, and Wei. koreensis. Additionally, it consisted of one unique isolate-Lac. curvatus. The LAB from the Ga, Gi, On, RPe, and WOn plants consisted of 48, 44, 52, 50, and 56 isolates representing 8, 8, 9, 9, and 9 species, respectively. All plants consisted of Leu. citreum, Leu. mesenteroides, Lac. plantarum, Lac. sakei, and Weu. confusa. Importantly, Lac. lactis and Wei. koreensis were represented in all plant samples except Ga and Won, respectively. The distribution of Wei. confusa was dominant in all plant samples, estimated at 33.3-51.8\% (Table 1).

Vegetables are naturally contaminated by eukaryotic (molds and yeasts) and prokaryotic (bacteria) organisms. The microbial community sizes and the relative species proportions on the vegetables vary in response to temperature variations, rainfall, insect- and mold-induced physical damage, and the use of insecticides and fungicides. Also, the microbial diversity of

Table 1 Distribution of endophytic lactic acid bacteria (ELAB) in each of the Chinese cabbage leaf and root, radish leave and root, welsh onion, onion, garlic, red pepper, and ginger samples

\begin{tabular}{|c|c|c|c|c|c|c|c|c|c|}
\hline \multirow{3}{*}{$\begin{array}{c}\text { Genus } \\
\text { Species }\end{array}$} & \multicolumn{9}{|c|}{ Distribution of ELAB in raw kimchi materials (\%)* } \\
\hline & \multicolumn{2}{|c|}{ Chinese cabbage } & \multicolumn{2}{|c|}{ Young radish } & \multirow{2}{*}{$\begin{array}{c}\text { Garlic } \\
{[48]}\end{array}$} & \multirow{2}{*}{$\begin{array}{c}\text { Ginger } \\
\text { [44] }\end{array}$} & \multirow{2}{*}{$\begin{array}{c}\text { Onion } \\
\text { [52] }\end{array}$} & \multirow{2}{*}{$\begin{array}{c}\text { Red } \\
\text { Pepper } \\
{[50]}\end{array}$} & \multirow{2}{*}{$\begin{array}{c}\text { Welsh } \\
\text { Onion } \\
{[56]}\end{array}$} \\
\hline & Leaf $[88]^{\dagger}$ & $\begin{array}{l}\text { Root } \\
{[92]}\end{array}$ & $\begin{array}{l}\text { Leaf } \\
{[40]}\end{array}$ & $\begin{array}{l}\text { Root } \\
{[45]}\end{array}$ & & & & & \\
\hline \multicolumn{10}{|l|}{ Leuconostoc } \\
\hline Le. carnosum ${ }^{1}$ & 7.1 & 2.2 & 2.5 & & & & & 2.0 & 1.8 \\
\hline Le. citreum ${ }^{2}$ & 6.8 & 7.8 & 7.5 & 7.5 & 8.3 & 11.4 & 3.8 & 6.0 & 7.1 \\
\hline Le. gasicomitatum ${ }^{2}$ & & & & 1.1 & & 2.3 & & & \\
\hline Le. gelidum ${ }^{2}$ & 7.1 & 5.5 & & & 3.8 & & & & 3.6 \\
\hline Le. inhae ${ }^{2}$ & 0 & 2.1 & & 1.1 & & & 1.9 & & \\
\hline Le. kimchii ${ }^{2}$ & 4.8 & & & 2.2 & & & & 2.0 & \\
\hline Le. mesenteroides ${ }^{1}$ & 7.1 & 10.6 & 17.5 & 13.3 & 12.6 & 6.8 & 7.7 & 6.0 & 5.4 \\
\hline \multicolumn{10}{|l|}{ Lactobacillus } \\
\hline Lb. brevis ${ }^{1}$ & & 5.2 & & 2.2 & 2.2 & & 1.9 & & \\
\hline Lb. curvatus ${ }^{2}$ & & & 2.5 & & & & & & 1.8 \\
\hline Lb. pentosus ${ }^{1}$ & & & & 2.2 & & & & & \\
\hline Lb. plantarum ${ }^{1}$ & 4.8 & 3.4 & 2.5 & 4.5 & 10.4 & 4.5 & 9.7 & 8.0 & 7.1 \\
\hline Lb. sakei ${ }^{1}$ & 7.1 & 8.3 & 5.0 & 4.5 & 14.6 & 9.1 & 7.7 & 10.0 & 8.9 \\
\hline \multicolumn{10}{|l|}{ Lactococcus } \\
\hline Lc. lactis $^{1}$ & 12.3 & 10.3 & 10.0 & 8.9 & & 13.6 & 13.5 & 16.0 & 12.5 \\
\hline \multicolumn{10}{|l|}{ Pediococcus } \\
\hline Pe. pentosaceus ${ }^{1}$ & & 2.1 & 2.5 & 2.2 & & & & & \\
\hline \multicolumn{10}{|l|}{ Weissella } \\
\hline We. confusa ${ }^{1}$ & 38.1 & 40.3 & 50.0 & 50.0 & 33.3 & 45.5 & 51.9 & 46.0 & 51.8 \\
\hline We. koreensis ${ }^{1}$ & 4.8 & 2.2 & & 2.5 & 2.2 & 6.8 & 1.9 & 4.0 & \\
\hline
\end{tabular}

${ }^{1}$ The specific LAB was identified by multiplex PCR method

${ }^{2}$ The specific LAB was identified by $16 \mathrm{~S}$ rRNA sequencing analysis

*Percentage of microcosmic each of in raw kimchi materials

Numbers in square brackets give the total number of the corresponding isolates in the samples 
Table 2 Change of lactic acid bacteria (LAB) during kimchi fermentation at $8{ }^{\circ} \mathrm{C}$ for 30 days

\begin{tabular}{|c|c|c|c|c|c|c|c|c|}
\hline \multirow{2}{*}{$\begin{array}{l}\text { Genus } \\
\text { Species }\end{array}$} & \multicolumn{8}{|c|}{ Distribution of LAB in kimchi fermentation day (\%)* } \\
\hline & $0[96]^{\dagger}$ & $3[96]$ & $6[96]$ & $9[96]$ & $12[96]$ & $18[96]$ & $24[96]$ & $30[96]$ \\
\hline \multicolumn{9}{|l|}{ Leuconostoc } \\
\hline Le. carnosum ${ }^{1}$ & 2.1 & 3.1 & 2.1 & & 2.1 & & & \\
\hline Le. citreum ${ }^{2}$ & 12.4 & 15.6 & 13.5 & 8.3 & 6.3 & 6.3 & 2.1 & \\
\hline Le. gasicomitatum ${ }^{2}$ & & & 3.1 & 8.3 & 12.6 & 16.7 & 17.7 & 5.2 \\
\hline Le. gelidum ${ }^{2}$ & 5.2 & 4.2 & & & 1.0 & & & \\
\hline Le. inhae ${ }^{2}$ & 2.1 & 1.0 & & 2.1 & 2.1 & 2.1 & & \\
\hline Le. kimchii ${ }^{2}$ & & 1.0 & 2.1 & 2.1 & 3.1 & & 2.1 & \\
\hline Le. mesenteroides ${ }^{1}$ & 4.2 & 8.3 & 12.6 & 14.6 & 9.4 & 8.3 & 2.1 & \\
\hline \multicolumn{9}{|l|}{ Lactobacillus } \\
\hline Lb. brevis ${ }^{1}$ & & & & 3.1 & 1.0 & & & \\
\hline Lb. curvatus $^{2}$ & & & 1.0 & & 1.0 & & & \\
\hline Lb. pentosus ${ }^{1}$ & & & & 1.0 & 2.1 & 3.1 & & \\
\hline Lb. plantarum ${ }^{1}$ & 3.1 & 4.2 & 5.2 & 7.3 & 8.3 & 5.2 & 10.4 & 12.6 \\
\hline Lb. sakei $i^{1}$ & 6.3 & 7.3 & 10.4 & 12.6 & 16.7 & 19.8 & 25.0 & 29.0 \\
\hline \multicolumn{9}{|l|}{ Lactococcus } \\
\hline Lc. lactis ${ }^{1}$ & 9.4 & 9.4 & 6.3 & 2.1 & & 2.1 & & \\
\hline \multicolumn{9}{|l|}{ Pediococcus } \\
\hline Pe. pentosaceus ${ }^{1}$ & & & & 1.0 & & & & \\
\hline \multicolumn{9}{|l|}{ Weissella } \\
\hline We. confusa ${ }^{1}$ & 55.2 & 45.9 & 39.5 & 29.2 & 11.4 & 8.3 & 6.3 & 10.4 \\
\hline We. koreensis ${ }^{1}$ & & & 4.2 & 8.3 & 22.9 & 28.1 & 34.3 & 42.8 \\
\hline
\end{tabular}

${ }^{1}$ The specific LAB was identified by multiplex PCR method

${ }^{2}$ The specific LAB was identified by $16 \mathrm{~S}$ rRNA sequencing analysis

* Percentage of microcosmic each of in the periods of mulkimchi fermentation

Numbers in square brackets give the total number of the corresponding isolates in the samples

vegetables can vary not only with raw materials, but also with environmental factors, such as growing area, soil, climate, season and harvest time etc. $[13,15]$. Vegetable-associated microorganisms may follow the different phases of flour preparation and are found in products made with flour [16]. Leuconostoc, Lactobacillus, Pediococcus and Weissella strains have frequently been observed in plant materials and fermented vegetables, particularly in the early phase of kimchi fermentation, and their populations throughout the fermentation period have been studied $[1,2,4,5,17]$.

\section{Change of LAB communities during the fermentation of mulkimchi}

To explore these data further, samples of mulkimchi were examined during fermentation ( 0 to 30 days) to characterize its LAB population using a similar experimental approach (Table 2). Leu. carnosum, Leu. citreum, Leu. gasicomitatum, Leu. gelidum, Leu. inhae, Leu. kimchi, Leu. mesenteroides, Lac. brevis, Lac. curvatus, Lac. pentosus, Lac. plantarum, Lac. sakei, Lac. lactis, Ped. pentosaceus, Wei. confusa, and Wei. Koreensis were prevalent throughout the fermentation process. At fermentation day 0 , the mulkimchi sample consisted of 9 species that included Leu. carnosum, Leu. citreum, Leu. gelidum, Leu. inhae, Leu. mesenteroides, Lac. plantarum, Lac. sakei, Lac. lactis, and Wei. confusa, which corresponded to the isolates represented in the raw vegetables. Importantly, the number of endophytic LAB species gradually increased up to fermentation day 12 (14 species, not including Lac. lactis, Pde. pentosaceus) and markedly decreased thereafter (5 species) until fermentation day 30. The distribution of endophytic LAB was dynamic during the fermentation periods examined. Specifically, the number of Wei. confusa isolates reached a maximum of $55.2 \%$ on day 0 , dramatically decreased to $11.4 \%$ by day 12 , and fluctuated thereafter to $10.4 \%$ by day 30 . Conversely, the viable Lac. sakei cell numbers gradually increased from $6.3 \%$ (0 days) to $29.0 \%$ (30 days) by the end of fermentation. Interestingly, the Lactobacillus sp. (including Lac. brevis, Lac. curvatus, and Lac. pentosus) appeared with Lac. plantarum and Lac. sakei at fermentation day 12, while all Lactobacillus sp. (not including Lac. curvatus) appeared at fermentation day 9. The existence of the maximum number of Lactobacillus sp. on fermentation days 9 through 12 may increase the production of lactic acid in mulkimchi. On fermentation day 6, an increase in viable Wei. koreensis cell numbers was measured, reaching a maximum value of $42.8 \%$ by the $30^{\text {th }}$ day. However, the number of LAB species, particularly Leu. carnosum, Leu. gasicomitatum, 


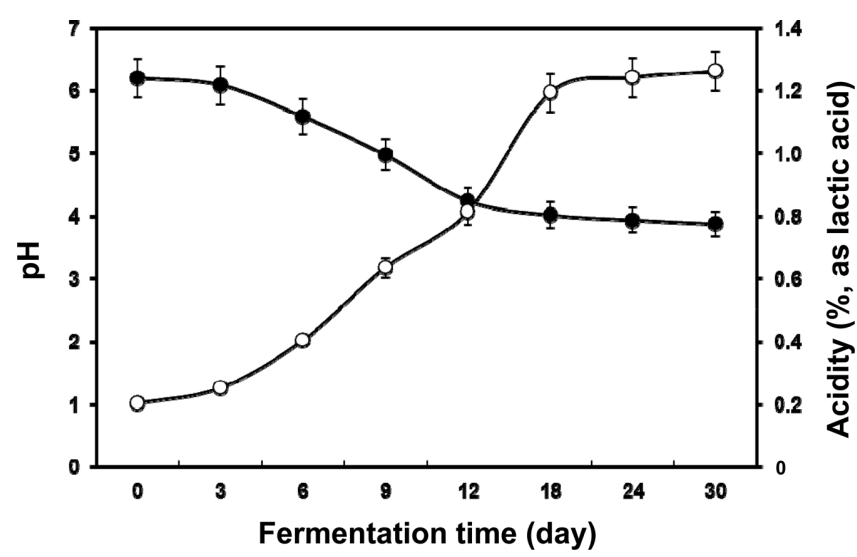

Fig. 1 Change of $\mathrm{pH}$ and acidity during mulkimchi fermentation at $8{ }^{\circ} \mathrm{C}$ for 30 days

Lac. brevis, Lac. curvatus, and Ped. pentosus, declined gradually after 18 days of fermentation.

A strong decrease in $\mathrm{pH}$ was observed (6.15 to 4.20$)$ during the first 2 weeks ( 0 to 12 days) and slowly decreased thereafter to 3.88 at fermentation 30 days. Conversely, the percentage of lactic acid dramatically increased up to 18 days ( 0.20 to 1.19$)$, and it was slightly increased thereafter to 1.26 at fermentation day 30 (Fig. 1).

The results showed that the $\mathrm{LAB}$ identified in the raw materials of the kimchi samples also appeared in the mulkimchi samples examined on different days of fermentation. Importantly, Lac. sakei is an acidophilic and/or acid-producing bacterium, which is phylogenetically close to Lac. plantarum. Therefore, viable cells of Lac. sakei and Lac. plantarum proportionally increased with the increase in acidity during mulkimchi fermentation. Moreover, the growth of others LAB were inhibited. A possible explanation is that the lower $\mathrm{pH}(4.02)$ or higher acidity (1.19\%) inhibited the growth of these LAB during the fermentation period. Therefore, the dynamic community of the LAB was observed throughout the fermentation period, which may have been associated with the total acidity produced by the acidophilic Lac. plantarum and Lac. sakei bacteria. Importantly, the lactic acid-producing Lac. sakei and Lac. plantarum bacteria were present throughout the fermentation process, indicating their prominent role in mulkimchi fermentation. A similar phenomenon with Lac. sakei and Lac. plantarum was previously observed during the fermentation of pogikimchi and mulkimchi $[3,17]$. Moreover, the proportion of Leu. mesenteroides and Lac. sakei increased gradually throughout the first week, but their prevalence decreased by the end of leek (vegetable) fermentation [18], which is partially consistent with the current study. Although a reduction in $\mathrm{pH}$ was observed, there was a gradual increase of Wei. koreensis throughout mulkimchi fermentation. This observation is consistent with the previously reported pogikimchi fermentation result [3]. These results indicate that the diversity of $\mathrm{LAB}$ isolates in raw materials is similar to that of mulkimchi during the early stage of fermentation. Therefore, these results were concluded that there is a flow of endophytic LAB into mulkimchi fermentation.

In conclusion, the endophytic LAB identified in raw vegetables corresponded to the LAB identified in mulkimchi samples examined on different days of fermentation. The predominance of Wei. confusa was observed in all raw vegetables examined and throughout the mulkimchi fermentation period. Specifically, the acid-producing Lac. sakei and Lac. plantarum bacteria became predominant as fermentation time and acidity increased during mulkimchi fermentation. These results suggest that the LAB involved in kimchi fermentation originate from its raw vegetables. Importantly, this study is the first to report the endophytic LAB community in kimchi raw vegetables using a multiplex PCR assay.

Acknowledgment This work was supported by Gyeongnam National University of Science and Technology Grant (2018 year), Republic of Korea.

\section{References}

1. Chin HS, Breidt F, Fleming HP, Shin WC, Yoon SS (2006) Identifications of predominant bacterial isolates from the fermenting kimchi using ITS-PCR and partial 16S rDNA sequence analyses. J Microbiol Biotechnol 16: 68-76

2. Cho JH, Lee DY, Yang CN, Jeon JI, Kim JH, Han HU (2006) Microbial population dynamics of kimchi, a fermented cabbage product. FEMS Microbiol Lett 257: 262-267

3. Cho KM, Math RK, Islam SMA, Lim WJ, Hong SY, Kim JM, Yun MG, Cho JJ, Yun HD (2009a) Novel multiplex PCR for the detection of lactic acid bacteria during kimchi fermentation. Mol Cell Prob 23: 90-94

4. Kim MJ, Chun JS (2005) Bacterial community structure in kimchi, a Korean fermented vegetable food, as revealed by 16S rRNA gene analysis. Int J Food Microbiol 103: 91-96

5. Lee JS, Heo GY, Lee JW, Oh YJ, Park JA, Park YH, Park YR, Pyun YR, Ahn JS (2005) Analysis of kimchi microflora using denaturing gradient gel electrophoresis. Int J Food Microbiol 102: 143-150

6. Lee MH, Yoo SH, Ha SD, Choi CS (2012) Inactivation of feline calicivirus and murine norovirus during Dongchimi fermentation. Food Microbiol 31: 210-214

7. Hong Y, Yang HS, Chang HC, Kim HY (2013) Comparison of bacterial community changes in fermenting kimchi at two different temperatures using denaturing gradient gel electrophoresis analysis. J Microbiol Biotechnol 23: 76-84

8. Jung JY, Lee SH, Jeon CO (2014) Kimchi microflora: history, current status, and perspectives for industrial kimchi production. Appl Microbiol Biotechnol 98: 2385-2393

9. Cagno RD, Coda R, de Angelis M, Gobbetti M (2013) Exploitation of vegetables and fruits through lactic acid fermentation. Food Microbiol 45: $1-10$

10. Jung JY, Lee SH, Kim JM, Park MS, Bae J-W, Hahn Y, Madsen EL, Jeon CO (2011) Metagenomic analysis of kimchi, a traditional Korean fermented food. Appl Environ Microbiol 77: 2264-2274

11. Patra JK, Das G, Paramithiotis S, Shin H-S (2016) Kimchi and other widely consumed traditional fermented foods of Korea: A review. Front Microbiol 7: 1493

12. Lee ME, Jang J-Y, Lee J-H, Park H-W, Choi H-J, Tae-Woon Kim T-W. (2015) Starter cultures for kimchi fermentation. J Microbiol Biotechnol 25: 559-568

13. Haque MA, Yun HD, Cho KM (2016) Diversity of indigenous 
endophytic bacteria associated with the roots of Chinese cabbage (Brassica campestris L.) cultivars and their antagonism towards pathogens. J Microbiol 54: 353-363

14. Cho KM, Math RK, Islam SMA, Lim WJ, Hong SY, Kim JM, Yun MG Cho JJ, Yun HD (2009b) Biodegradation of chlorpyrifos by lactic acid bacteria during kimchi fermentation. J Agric Food Chem 57: 1882-1891

15. Haque MD, Lee JH, Cho KM (2015) Endophytic bacterial diversity in Korean kimchi made of Chinese cabbage leaves and their antimicrobial activity against pathogens. Food Con 56: 24-33
16. Corsetti A, Settanni L (2007) Lactobacillus in sourdough fermentation. Food Res Int 40: 539-558

17. Kim B, Seo WT, Kim MG, Yun HD, Cho KM (2012) Metagenomic lactic acid bacterial diversity during mulkimchi fermentation based on 16S rRNA sequence. J Korean Soc Appl Biol Chem 55: 787-792

18. Wouters D, Bernaert N, Conjaerts W, Van Droogenbroeck B, De Loose M, de Vuyst L (2013) Species diversity, community dynamics, and metabolite kinetics of spontaneous leek fermentations. Food Microbiol 33: 185-196 